\title{
Integrated approach to industrial sewage water treatment - a way of water resources rational use and protection
}

\author{
Evgeny Alekseyev ${ }^{1, *}$ and Valery Volshanik ${ }^{1}$ \\ ${ }^{1}$ Moscow State University of Civil Engineering, 129337, Yaroslavskoye Shosse 26, Moscow, Russia
}

\begin{abstract}
Ion-exchange softening plants wash water treatment studies are provided in order to bring them back to the process. Poorly soluble $\mathrm{Ca}$ and $\mathrm{Mg}$ compounds formation conditions have been studied during the course of such water caustic treatment using the potentiometric titration method. Information has been provided about the $\mathrm{Ca}$ and $\mathrm{Mg}$ hydroxide sludge sorption properties with regard to the characteristic contaminants of the sewage water generated by the textile industry enterprise. Suitability of the hydroxide sludge has been established for use in the sewage water treatment technology in order to remove the persisting organic compounds, such as the synthetic dyes.
\end{abstract}

\section{Introduction}

The waterworks system in multiple enterprises is a consumer of large quantities of softened water. Depending on the enterprise profile, the demand in the softened water may reach as much as $40 \%$ of total water consumption.

At the ion-exchange softening plants, the cation exchanger regeneration after depletion of its exchange capacity is accomplished using 5-10\% $\mathrm{NaCl}$ solution, as follows:

$$
\begin{gathered}
{[\mathrm{K}] 2 \mathrm{Ca}+2 \mathrm{NaCl} \leftrightarrow 2[\mathrm{~K}] \mathrm{Na}+\mathrm{CaCl} 2,} \\
{[\mathrm{~K}] 2 \mathrm{Mg}+2 \mathrm{NaCl} \leftrightarrow 2[\mathrm{~K}] \mathrm{Na}+\mathrm{MgCl} 2}
\end{gathered}
$$

These reactions result in that the $\mathrm{Cl}$ anions and $\mathrm{Ca} \& \mathrm{Mg}$ cations that form the hardness salts are transferred to the wash water. Their content in the wash water may reach as much as $600 \mathrm{mg}$.equiv/l and more. The income of the large quantity of the hardness salts into the enterprise sewage water limits its repeated use in the production processes and stipulates the need to extract them during the course of the common sewage water flow treatment. It should be appreciated that the aqueous system formed by this water is related to the stable type containing the conservative mineral and persistent organic substances. Treatment of such water is accompanied by large-scale consumption of reagents and energy [1-2]. Owing to that, it is reasonably practicable to consider a possibility to recover and bring back or return the ion-exchange plants wash water into the process by means of hardness salts

*Corresponding author: AlexeevE@mgsu.ru 
sedimentation. This excludes their mixing with the common sewage water flow and negative impact on its chemical composition. On the other hand, the possibility of using this resulting sludge as sorbents for extraction of organic contaminants from the other local industrial sewage water flows shall be evaluated as well [6-8].

Extraction of $\mathrm{Ca}$ and $\mathrm{Mg}$ from the wash water is principally possible in the form of sediments using various reagents that form poorly soluble compounds [3-4].

For these studies, the sedimentizing reagents have been chosen that are rather cheap, available, and applicable in the textile industry enterprises processes $[9,12]$. Meanwhile, it is undesirable to use the substances that enrich the water with chemical interaction products that deteriorate its quality in significant manner. Therefore, the following substances have been adopted: $\mathrm{Na}_{2} \mathrm{CO}_{3}, \mathrm{NaOH}$, and $\mathrm{Ca}(\mathrm{OH})_{2}$.

The $\mathrm{Ca}$ and $\mathrm{Mg}$ compounds contained in the wash solutions form the poorly soluble compounds with these adopted reagents, as follows:

$$
\begin{aligned}
& \mathrm{CaCl} 2+\mathrm{Na} 2 \mathrm{CO} 3 \rightarrow \mathrm{CaCO} 3 \downarrow+2 \mathrm{NaCl} \\
& \mathrm{MgCl} 2+\mathrm{Na} 2 \mathrm{CO} 3 \rightarrow \mathrm{MgCO} 3 \downarrow+2 \mathrm{NaCl} \\
& \mathrm{CaCl}_{2}+2 \mathrm{NaOH} \rightarrow \mathrm{Ca}(\mathrm{OH})_{2} \downarrow+2 \mathrm{NaCl} \\
& \mathrm{MgCl}_{2}+2 \mathrm{NaOH} \rightarrow \mathrm{Mg}(\mathrm{OH})_{2} \downarrow+2 \mathrm{NaCl}
\end{aligned}
$$

In general case, these reactions provide simultaneous extraction of $\mathrm{Ca}$ and $\mathrm{Mg}$ sludge within a single stage. Meanwhile, weight ratio between $\mathrm{Ca}(\mathrm{OH})_{2}$ and $\mathrm{Mg}(\mathrm{OH})_{2}$ in the sludge or sediment will depend on their content in the wash water, hydroxide form solubility, and sufficiency of the sedimentizing reagents quantity [5].

The summarized data concerning the solubility properties of the sludge formed through the reactions (1) are provided in table 1.

Table 1. Solubility of $\mathrm{Ca}$ and $\mathrm{Mg}$ hydroxides and carbonates

\begin{tabular}{|c|c|c|}
\hline Poorly soluble compound & Solubility product (SP) & $\begin{array}{c}\text { Water hardness after } \\
\text { sedimentizing, mg-equiv/1 }\end{array}$ \\
\hline $\mathrm{CaCO}_{3}$ & $4.8 \cdot 10^{-9}$ & 0.035 \\
\hline $\mathrm{Ca}(\mathrm{OH})_{2}$ & $3.1 \cdot 10^{-5}$ & 5.55 \\
\hline $\mathrm{MgCO}{ }_{3}$ & $1.0 \cdot 10^{-5}$ & 2.54 \\
\hline $\mathrm{Mg}(\mathrm{OH})_{2}$ & $5.0 \cdot 10^{-12}$ & 0.065 \\
\hline
\end{tabular}

Since the sewage water of the water softening plant in the most general case contains both $\mathrm{Ca}$ salts, and $\mathrm{Mg}$ salts, in the experiments accomplished $\mathrm{NaOH}$ has been used as the reagent efficient for both ions sedimentizing.

In addition to the main objective - determination of optimal conditions for sludge formation - another point of interest was the use of neutralization potentiometric titration method for identification of the content values and conversion of the water permanent hardness components $[10,11,13]$.

Potentiometric studies of the complex sediments formation process have been accomplished using the titration of the $\mathrm{Ca}$ and $\mathrm{Mg}$ salts solutions blends with $\mathrm{NaOH}$. These measurements have been accomplished for different ratios of $\mathrm{Ca}$ and $\mathrm{Mg}$ in the blends, as well as for the samples of water delivered to the water softening plant of the worsted and wool products enterprise. The results of measurements are illustrated in Fig. 1A. 

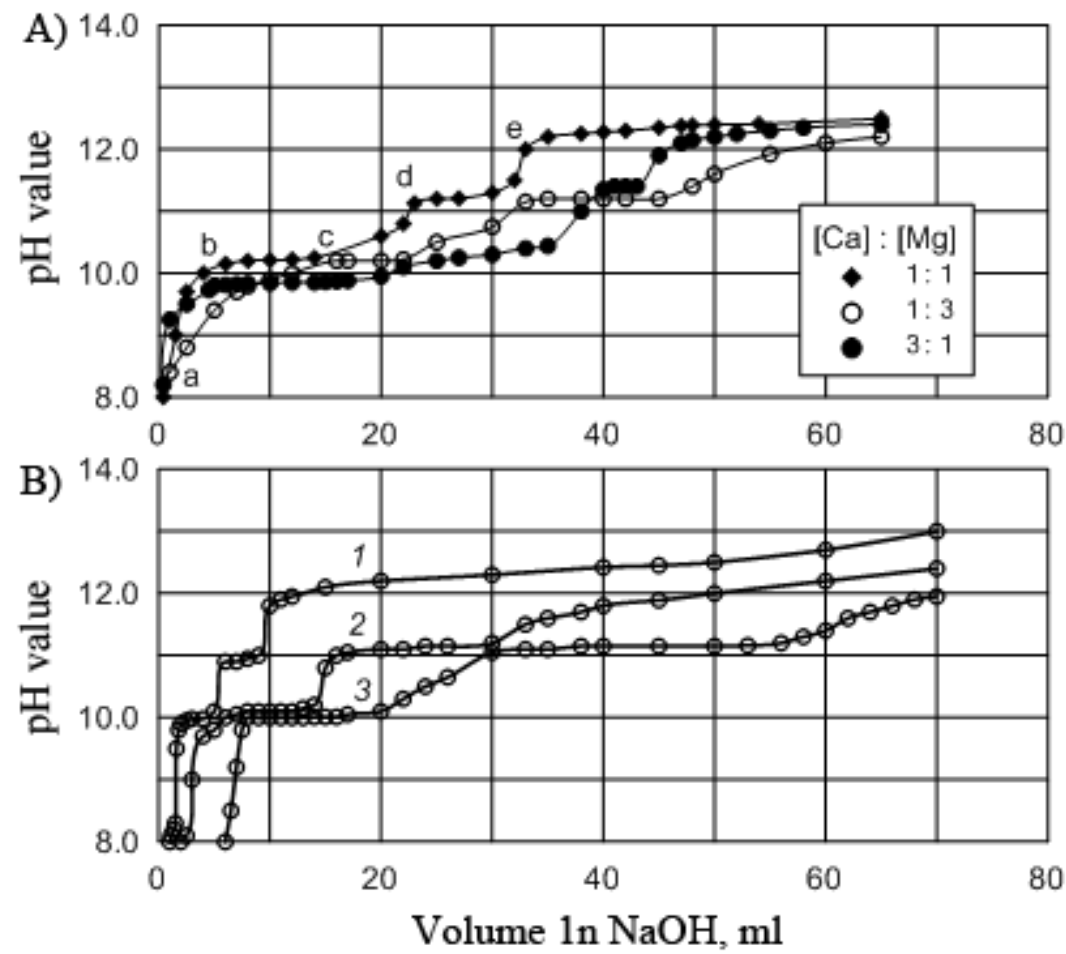

Fig. 1. Titration potentiometric curves: $\mathrm{A}-\mathrm{Ca}$ and $\mathrm{Mg}$ salts blends with various $[\mathrm{Ca}]:[\mathrm{Mg}]$ ratios; $\mathrm{B}$ wash water of the Na cation exchanger with the following hardness values: 1 - $50 \mathrm{mg}$-equiv/l; 2 $260 \mathrm{mg}$-equiv/1; 3 - $480 \mathrm{mg}$-equiv/l.

The analysis of the given dependencies allows revealing main regularities of the sedimentizing from the solutions that contain both $\mathrm{Ca}$ salts, and $\mathrm{Mg}$ salts. The resulting curves are characterized by sufficient selectivity for quantitative estimate of the formed compounds with the acceptable degree of accuracy. As such, the ratio between the standard solution (titrant) volumes at $b-c$ and $d$-e sections rather well accords with the ratio between the $\mathrm{Ca}$ and $\mathrm{Mg}$ concentrations established by chemical analysis.

Ion-exchange filters wash water for the study has been taken from the enterprise softening plant draw-off conduit. The results of the hydroxides sedimentizing from the wash water having the permanent hardness equal to 50,260 , and $480 \mathrm{mg}$-equiv/l are illustrated in Fig. 1B.

During the course of the wash water titration, the point when the flakes begin to form occurs with the $\mathrm{pH}$ change within 10.1-10.3 range. This value remains unchanged when the volume of the added caustic increases, while the significant increase in the formed dispersion quantity is noted. Further titration leads to the $\mathrm{pH}$ increase up to as much as 11.0-11.2; after that, the $\mathrm{pH}$ value is stabilized and forms the second semi-wave. In this range, the structure of the formed sludge changes. By comparing the resulting dependencies of the wash water titration with the $\mathrm{Ca}$ and $\mathrm{Mg}$ standard solutions titration curves (see Fig. 1A), one can see rather close position of the semi-wave in terms of $\mathrm{pH}$ value that correspond to the $\mathrm{Ca}$ and $\mathrm{Mg}$ hydroxides formation. Meanwhile, good harmonization of the caustic volumes spent for titration within the first and second semi-waves with the corresponding water permanent hardness value should be noted. The analysis of the resulting curves allows determining the equivalent ratio between the $\mathrm{Ca}$ and $\mathrm{Mg}$ ions. For the studied wash water, this ratio approximately equals to $1: 2$.

The potentiometric titration curves for the wash water from the ion-exchange filters 
regeneration operations enable to determine the optimal $\mathrm{pH}$ area and the required quantity of caustic for the $\mathrm{Ca}$ and $\mathrm{Mg}$ hydroxides sedimentizing.

The evaluation of the suitability of the hydroxide sludge obtained from the wash water for use in the industrial sewage water reagent-based treatment technology has been accomplished on real-life dyeing and finishing sewage water. The sorption parameters of extraction from the sewage water of the industry-wide used dyes, such as active, sulfix, direct, and disperse, have been studied.

The processing of the dyes sorption results with the $\mathrm{Ca}$ and $\mathrm{Mg}$ hydroxides using the Langmuir isotherm has enabled to determine the marginal adsorption average values, as illustrated in table 2 .

Table 2. Marginal adsorption average values for various types of dyes on $\mathrm{Ca}$ and $\mathrm{Mg}$ hydroxides

\begin{tabular}{|l|c|c|}
\hline \multirow{2}{*}{ Dye class } & \multicolumn{2}{|c|}{ Marginal adsorption, mg/mg-equiv } \\
\cline { 2 - 3 } & $\mathrm{Mg}(\mathrm{OH})_{2}$ & $\mathrm{Ca}(\mathrm{OH})_{2}$ \\
\hline Active & 2.04 & 3.86 \\
\hline Sulfix & - & 0.615 \\
\hline Direct & 10.63 & 1.73 \\
\hline Disperse & 23.84 & 13.68 \\
\hline
\end{tabular}

The most of efficiency in extraction of dyes from the sewage water is noted when using the $\mathrm{Mg}(\mathrm{OH})_{2}$ sludge. The exception is the sulfix class dyes, where rate of extraction by the sludge disperse phase is rather poor.

By comparing the marginal adsorption values, one can see that the deepest cleansing of water from active, direct, and disperse dyes may be provided when using the $\mathrm{Mg}$ and $\mathrm{Ca}$ hydroxides simultaneously.

In order to evaluate the efficiency of the sludge extracted from the ion-exchange filters exhausted regenerative solutions, a number of experiments using the settling tank as the separating stage have been accomplished in the textile industry enterprise real-life sewage water treatment system. The quality of the treated water has been evaluated using the standard methods in the samples taken after 60 min of settling (Fig. 2).

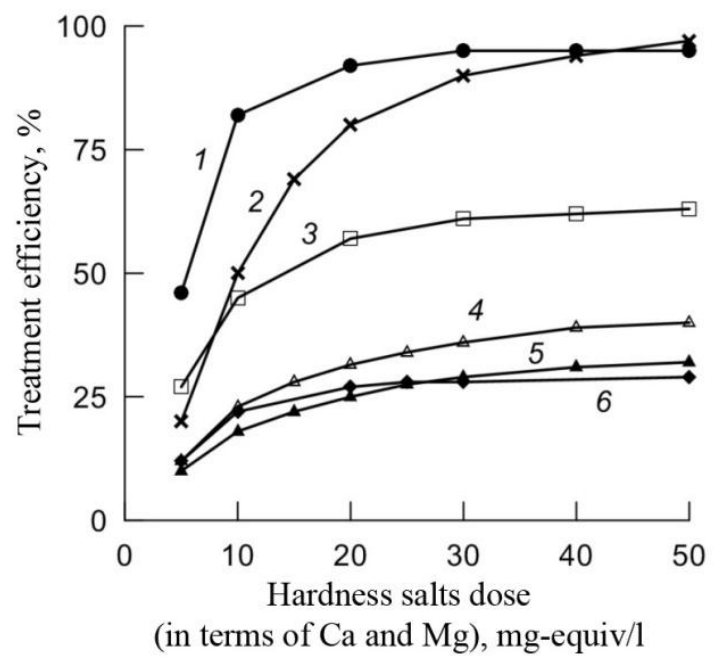

Fig. 2. Influence of the hardness salts dose onto the industrial sewage water treatment efficiency: 1 - color upon dilution; 2 - suspended solids; 3 - chemical oxygen demand (COD);4 - anionic surfactants; 5 - non-ionogenic surfactants; 6 - petroleum products. 
The analysis of the resulting dependencies leads to a conclusion that the interaction of the real-life sewage water contaminants with the fresh $\mathrm{Ca}$ and $\mathrm{Mg}$ hydroxides sludge occurs via the adsorption mechanism. The most of the treatment efficiency (over $90 \%$ ) has been achieved for hard disperse impurities adsorbed by the hydroxides at the structure formation moment, and for the dyes. Extraction of hydrocarbons, such as the petroleum products and surfactants, does not exceed $40 \%$, which may be explained by the hydrophilic nature of $\mathrm{Ca}$ and $\mathrm{Mg}$ hydroxides. The change of the COD value is adequate to the extraction of the organic part of the contamination.

The results obtained have confirmed the possibility to use the ion-exchange softening plants wash water for treatment of the sewage water flow generated by the textile industry enterprises dying shops before the mixing of such flow with the common flow.

\section{Conclusion}

The reasonability of the separation of the softening plants sewage water flow from the common flow and $\mathrm{Ca} \& \mathrm{Mg}$ salts sedimentizing has been justified using the experimental approach. It has been shown that the potentiometric titration curves for the wash water from the ion-exchange filters regeneration operations enable to determine the optimal $\mathrm{pH}$ area and the required quantity of caustic for the $\mathrm{Ca}$ and $\mathrm{Mg}$ hydroxides sedimentizing. The separation of the sewage water flow from the water ion-exchange softening plants in the industrial enterprises water disposal system enables to use such flow as the sedimentizing solution in the sewage water treatment processes, when such sewage water contains dyes. This integrated technological solution provides for the reduction of water consumption owing to the return or bringing back the wash water into the water treatment process, reduction of costs spent on the reagents for the industrial waste water common flow treatment, and reduction of the contaminants or impurities ingress into the environment.

\section{References}

1. E.V. Alekseyev, Vestnik MGSU, 2, 140-144 (2012)

2. E.V. Alekseyev, Water and Ecol.: Probl. and Solut., 4, 68-79 (2015)

3. L.S. Grigoryeva, Physical and chemical evaluation of the natural water quality and natural water treatment (Publ. House of the Const. Higher Educ. Inst. Ass., 2011)

4. V.I. Sidorov, E.P. Aganesyan, T.P. Nikiforova, Chemistry in construction (Publ. House of the Const. Higher Educ. Inst. Ass., 2007)

5. E.V. Alekseyev, Physical and chemical treatment of sewage water (Publ. House of the Const. Higher Educ. Inst. Ass., 2007)

6. E. Gogina, A. Pelipenko, MATEC Web of Confer. 73 (2016)

7. A.G. Pervov, A.P. Andrianov, T.P. Gorbunova, A.S. Bagdasaryan, Petrol. Chem. 55, 879-886 (2015)

8. N. Makisha, Y. Voronov, E. Poupyrev, V. Volshanik, Inter. Journal of App. Eng. Res. 10, 41919-41922 (2015)

9. I. Kantardgi, V. Maderich, E. Terletskaya, I. Brovchenko, L. Prokhoda-Shumskikh, MEDCOAST 2013 Joint Conference, 2, 989-1000 (2013)

10. N.V. Suikova, Y.V. Bryanskaya, V.S. Borovkov, Water Res. 39, 200-207 (2012)

11. A.G. Pervov, A.P. Andrianov, E.B. Yurchevskiy, Petr. Chem. 55, 871-878 (2015)

12. N. Zaletova, S. Zaletov, Inter. Journal of App. Eng. Res. 10, 43873-43874 (2015)

13. N. Makisha, V. Scherbakov, A. Smirnov, E. Scherbina, Inter. Journal of App. Eng. Res. 10, 44347-44349 (2015) 